\title{
Factors associated with risk of low dietary fiber intake in adolescents
}

\author{
Márcia R. Vitolo, ${ }^{1}$ Paula D. B. Campagnolo, ${ }^{2}$ Cíntia M. Gama ${ }^{3}$
}

\begin{abstract}
Objective: To evaluate dietary fiber intake among adolescents and to analyze factors associated with the risk of insufficient consumption of this nutrient.

Methods: Cross-sectional study of 722 adolescents from the town of São Leopoldo, RS, Brazil. Sampling was by clusters, with a systematic randomization of 40 census sectors and residences, including all individuals aged 10 to 19 years. The adolescents' weight and height were measured and sociodemographic data on their families recorded. A 24-hour dietary recall and a frequency survey were used to assess dietary intakes. The quantity of dietary fiber in diets was calculated using Nutwin nutrition support software (Programa de Apoio à Nutrição), developed by the IT Department at Universidade Federal de São Paulo (UNIFESP). Statistical analysis was by means of logistic regression, employing a hierarchical model.
\end{abstract}

Results: The prevalence of insufficient dietary fiber intake was $69 \%$ among girls and $49.7 \%$ for boys $(p<0.001)$. The determinant factors of this condition among boys were non-habitual consumption of beans (OR $2.65 ; 95 \% \mathrm{CI}$ 1.05-6.68) and excessive fat intake (OR 2.67; 95\%CI 11.23-5.83). For girls factors were increased age (OR 5.33; $95 \%$ CI 2.33-12.2), non-habitual consumption of beans (OR 3.01; 95\%CI 1.44-6.53), excessive fat intake (OR 1.85; $95 \%$ CI 1.01-3.37), dieting for weight loss (OR 2.50; 95\%CI 1.10-5.70) and presence of overweight (OR $2.06 ; 95 \% \mathrm{CI}$ 1.04-4.07).

Conclusions: These results admit of the conclusion that excessive fat consumption and non-habitual consumption of beans are strongly linked with the risk of insufficient dietary fiber intake in both sexes and that females exhibit a greater number of risk factors for this outcome.

J Pediatr (Rio J). 2007;83(1):47-52: Dietary fiber, constipation, obesity, adolescents.

\section{Introduction}

Dietary fiber can play a role in the prevention of intestinal diseases, such as constipation, hemorrhoids, hiatus hernia, diverticular disease and cancer of the colon.

1. Professor adjunto, Programa de Pós-Graduação em Ciências Médicas, Fundação Faculdade Federal de Ciências Médicas de Porto Alegre (FFFCMPA), Porto Alegre, RS, Brasil.

2. Nutricionista. Mestre, Programa de Pós-Graduação em Ciências Médicas, FFFCMPA, Porto Alegre, RS, Brasil.

3. Professor adjunto, Departamento de Saúde Coletiva, FFFCMPA, Porto Alegre, RS, Brasil.

Manuscript received Mar 30 2006, accepted for publication Aug 042006.

Suggested citation: Vitolo MR, Campagnolo PD, Gama CM. Factors associated with a risk of low dietary fiber intake in adolescents. J Pediatr (Rio J). 2007;83(1):47-52.

doi 10.2223/JPED.1582
It can also contribute to the prevention and treatment of obesity, reduction of blood cholesterol levels, glycemic regulation after meals and even reduce the risk of cardiovascular diseases and diabetes. ${ }^{1}$

adolescence is a period of risk for the adoption of nutritional habits that result in excessive energy density and deficiencies of certain nutrients, including dietary fiber. $^{2-4}$ studies of Brazilian families' nutritional intake habits have not evaluated dietary fiber intake, ${ }^{5}$ and neither have adolescents been studied, ${ }^{6,7}$ in contrast with data from other countries, which provide intake values of between 15 and $19.6 \mathrm{~g}^{8-10}$ Brazilian studies that have investigated dietary fiber intake among children and adolescents have involved individuals at clinics, outpatients and schools, with the aim of studying the etiologic factors of 
intestinal constipation. ${ }^{11-14}$ These studies have reported fiber intake levels of from 3.4 to $15.5 \mathrm{~g}$ per day, although the patient samples studied ranged from infants to adolescents, and there are methodological differences in terms of the dietary surveys and types of fiber employed. Faced with this paucity of sufficient Brazilian data on the subject, the objective of this study was to evaluate dietary fiber intake among adolescents of both sexes and the factors associated with it.

\section{Methods}

Cross-sectional study with representative sample of the adolescent residents of São Leopoldo, RS, Brazil. Sample size was calculated based on an $18 \%$ assumed prevalence of overweight, ${ }^{15,16}$ a confidence level of $95 \%$ and statistical power of $80 \%$, with an extra $10 \%$ added for possible losses, and $15 \%$ for the multivariate analysis, which resulted in a sample size of 807 adolescents. Adolescents were excluded if they were pregnant, nursing or mothers, as were adolescents with physical or mental disabilities or chronic pathologies.

Sampling was performed by clusters in three stages. All individuals living at the homes chosen and aged between 10 and 19 years were identified and invited to take part in the project. The parents or the adolescent themselves refused to take part in $8.6 \%(n=70)$ of cases, $1.8 \%(n=15)$ could not be located at home after three attempts, and $0.3 \%$ $(n=3)$ had moved house, making a total of $11 \%$ of losses. Losses were greater among males, accounting for $85 \%$ $(n=60)$ of refusals. In sectors where the prevalence of illiteracy was below $5 \%$, percentage of losses was $24.5 \%$, while in sectors where more than $5 \%$ of the population are illiterate, the percentage of losses was $17.5 \%$.

A pre-coded questionnaire was developed covering socioeconomic, biological, familial, anthropometric and nutritional factors, and this was applied and filled out by specially trained researchers, irrespective of the age of the adolescent. A pilot study was conducted of 60 adolescents from sectors that were not chosen in the sampling process.

Fat and fiber intake were quantified using a 24-hour dietary recall with the aid of a photo album contain color photographs of utensils and foods, developed specifically for this project, with the objective of better quantifying the portions adolescents eat. A frequency questionnaire was also used to assess consumption of beans, vegetables and fruit.

Fat and dietary fiber intakes were calculated using Nutwin nutrition support software (Programa de Apoio à Nutrição), developed by the UNIFESP IT department, in addition to information obtained from the food industry on products not listed in the tables. Adequate fat intake was defined according to the World Health Organization (WHO) recommendation, ${ }^{17}$ which defines a proportion of up to $30 \%$ of the total energy content of the diet. Adequate dietary fiber intake was defined according to Williams, who suggests the formula age $+5 .{ }^{18}$

Consumption of beans, vegetables and fruit was considered habitual when adolescents ate these foods four or more times a week, the criterion established for this study. Constipation was defined by less than three defecations a week and hard or round cracked stools, in addition to difficulty to evacuate without laxatives was reported.

Portable electronic scales were used to weigh subjects. Adolescents were weighed wearing a light clothes, such as shorts for boys and shorts and T-shirt for girls. Height was measured using a stadiometer with a built-in tape measure. Nutritional status was classified by body mass index (BMI) against the National Center for Health and Statistics reference curves and according to WHO criteria, ${ }^{19}$ which considers adolescents with BMI percentiles above the 85th to be overweight.

Mean fiber intake was compared across the three age groups using the Kruskal-Wallis test and between sexes with the Mann-Whitney test. Multivariate analysis was performed by logistic regression, employing a hierarchical model (Figure 1), calculating odds ratios (OR) and $95 \%$ confidence intervals $(95 \% \mathrm{CI})$. Odds ratios were used to measure effect, in the knowledge that they are mildly superior to prevalence ratios when gauging risk factors, and inferior when evaluating protective factors. Variables were added to the regression model when they attained a significance of $20 \%$, and their associations were considered significant if they reached $5 \%$. Those variables which exhibited significance were retained in the analysis for following levels.

This project was approved by the Research Ethics Committee at the Universidade Federal do Rio Grande do Sul.

\section{Results}

Complete and valid dietary recall data were obtained for 722 adolescents ( $89 \%$ of the entire sample), $59 \%$ of whom were girls. Mean age of the boys was 14.2 \pm 2.6 , and for the girls it was $14.5 \pm 2.8$ years. With respect of maternal education, $28 \%$ had spent 4 years or less at school and $34.4 \%$ had studied for more than 8 years. The prevalence of overweight was $17.8 \%$, and intestinal constipation prevalence was $22.9 \%$.

The prevalence of fiber intake below the recommended level was $61.2 \%$ for total sample, $69 \%$ for girls and $49.7 \%$ 

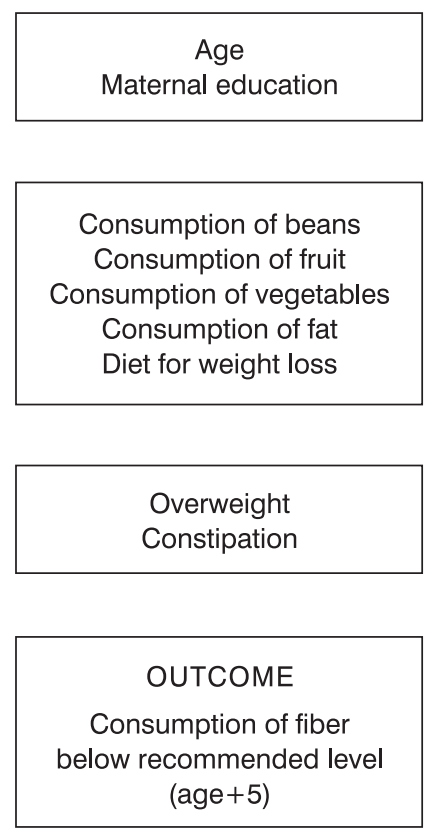

Figure 1 - Hierarchical model

for boys ( $p<0.001)$. Mean fiber intakes by sex were $21.5 \mathrm{~g}$ for boys and $16.9 \mathrm{~g}$ for girls $(\mathrm{p}<0.001)$. When stratified by age group, boys aged 10 to 12 ate an average of $19.8 \pm 11.1$ $\mathrm{g}$; those from 13 to 15 had mean intake of $22.1 \pm 12.9 \mathrm{~g}$; and those aged 16 to 19 ate an average of $23.2 \pm 22.1 \mathrm{~g}$, and the differences between age groups were not significant ( $p=$ 0.448). Among the girls, mean dietary fiber intake of girls aged 10 to 12 years $(18.3 \pm 10.9 \mathrm{~g})$ was significantly greater $(p=0.039)$ than the mean intake of girls aged 16 to 19 years $(15.1 \pm 8.8 \mathrm{~g})$.

Table 1 contains both crude and adjusted analyses of the effect on the outcome of exposure to independent variables for the female sex. Girls aged 16 to 19 years exhibited increased chance of eating less than the recommended quantity of fiber. Among the dietary variables investigated, non-habitual consumption of beans and excessive fat consumption were associated with fiber intake below the recommendation. Overweight girls and those who had already tried some type of diet for weight loss exhibited increased frequency of lower than recommended dietary fiber intake.

The same results for boys are shown in Table 2. The adjusted analysis demonstrates that among boys non-habitual consumption of beans and excessive fat consumption were also associated with fiber intake below the recommendation.

Neither the presence of intestinal constipation nor fruit and vegetable consumption were associated with lower than recommended dietary fiber intakes for either sex.

\section{Discussion}

Our study identified mean dietary fiber intake levels that are within the same range as figures from the European continent, ${ }^{8,10,20}$ where female adolescents also eat less fiber than males. Notwithstanding, the mean dietary fiber intake observed in this investigation, for the male sex (21.5 $\mathrm{g})$, is greater than was observed in those studies.

The influence of sex on the results observed opens new perspectives for investigations that involve dietary behavior at risk of insufficient dietary fiber consumption. The results suggest that non-habitual consumption of beans is a risk factor for insufficient dietary fiber intake for both sexes, which result is compatible with the few studies undertaken in Brazil that have evaluated dietary fiber intake among adults. It was demonstrated that beans are the primary source of dietary fiber among adults and that there was a statistical difference between sexes. The mean consumption of fiber was $20 \mathrm{~g}$ among women and $29 \mathrm{~g}$ among men. ${ }^{6,7}$ This condition may have onset at the end of adolescence, considering that, in this study, older adolescents (16-19 years) consumed less dietary fiber than younger ones.

Eating a diet containing more than $30 \%$ energy from fat was associated with the risk of insufficient dietary fiber intake for both sexes. Since this is a cross-sectional study, it is not possible to identify whether the reduced consumption of fiber leads to increased fat intake, or vice-versa. Nevertheless, the results confirm the risk of exposure to 
non-transmissible chronic diseases to which these adolescents are subjected. 5,21,22

Despite evidence that there is an association between lower dietary fiber intake and overweight, ${ }^{23-26}$ in this study it was only possible to detect this association in the female sex, which is compatible with the results of a study with adolescents in southern Spain. ${ }^{27}$
It is important to point out that the failure of this study to detect an association between intestinal constipation and inadequate dietary fiber intake does not indicate that fiber intake does not play a favorable role in adolescent intestinal function. Other factors, in addition to insufficient fiber intake (practicing physical exercise and adequate consumption of fluids), are related to the etiology of

Table 1 - Crude and adjusted analyses of factors associated with insufficient dietary fiber intake in girls

\begin{tabular}{|c|c|c|c|}
\hline \multirow[t]{2}{*}{ Exposure variable } & \multicolumn{3}{|c|}{ Insufficient dietary fiber intake } \\
\hline & $\%$ & Crude OR $(95 \% \mathrm{CI})$ & Adjusted OR ( $95 \% \mathrm{CI})$ \\
\hline \multicolumn{4}{|l|}{ Age } \\
\hline $13-15$ years (vs. $10-12$ years) & 68.8 & $1.74(1.05-2.89)$ & $1.66(0.83-3.34)$ \\
\hline $16-19$ years (vs. $10-12$ years) & 83.8 & $4.08(2.26-7.42)$ & $5.33(2.33-12.2)$ \\
\hline \multicolumn{4}{|l|}{ Maternal education } \\
\hline $5-8$ years (vs. $\leq 4$ years) & 67.7 & $1.19(0.70-2.02)$ & $1.29(0.63-2.64)$ \\
\hline$>8$ years (vs. $\leq 4$ years) & 75.5 & $1.75(0.99-3.04)$ & $2.09(0.95-4.70)$ \\
\hline Non-daily consumption of fruit & 72.0 & $1.56(0.99-2.46)$ & $1.37(0.74-2.54)$ \\
\hline Non-daily consumption of vegetables & 70.4 & $1.82(0.95-3.50)$ & $2.00(0.93-4.31)$ \\
\hline Non-habitual consumption of beans & 84.5 & $3.44(2.06-5.74)$ & $3.01(1.44-6.53)$ \\
\hline Fat consumption $>30 \% *$ & 72.1 & $1.37(0.90-2.07)$ & $1.85(1.01-3.37)$ \\
\hline Diet for weight loss & 80.7 & $2.25(1.32-3.82)$ & $2.50(1.10-5.70)$ \\
\hline BMI $\geq 85$ th percentile & 80.8 & $2.08(1.11-3.88)$ & $2.06(1.04-4.07)$ \\
\hline Constipation & 71.6 & $1.13(0.70-1.81)$ & $1.59(0.77-3.28)$ \\
\hline
\end{tabular}

Table 2 - Crude and adjusted analyses of factors associated with insufficient dietary fiber intake in boys

\begin{tabular}{|c|c|c|c|}
\hline \multirow[t]{2}{*}{ Exposure variable } & \multicolumn{3}{|c|}{ Insufficient dietary fiber intake } \\
\hline & $\%$ & Crude OR (95\%CI) & Adjusted OR (95\%CI) \\
\hline \multicolumn{4}{|l|}{ Age } \\
\hline $13-15$ years (vs. $10-12$ years) & 48.5 & $1.07(0.60-1.90)$ & $1.32(0.56-3.11)$ \\
\hline $16-19$ years (vs. $10-12$ years) & 56.6 & $1.48(0.79-2.78)$ & $1.53(0.56-4.20)$ \\
\hline \multicolumn{4}{|l|}{ Maternal education } \\
\hline $5-8$ years (vs. $\leq 4$ years) & 46.3 & $1.06(0.57-1.98)$ & $1.25(0.48-3.23)$ \\
\hline$>8$ years (vs. $\leq 4$ years) & 55.0 & $1.50(0.79-2.85)$ & $1.12(0.41-3.05)$ \\
\hline Non-daily consumption of fruit & 49.7 & $1.21(0.71-2.06)$ & $1.60(0.75-3.43)$ \\
\hline Non-daily consumption of vegetables & 51.4 & $1.58(0.56-4.54)$ & $1.54(0.46-5.19)$ \\
\hline Non-habitual consumption of beans & 71.3 & $3.50(2.00-6.09)$ & $2.65(1.05-6.68)$ \\
\hline Fat consumption $>30 \% *$ & 59.5 & $2.3(1.44-3.69)$ & $2.67(1.23-5.83)$ \\
\hline Diet for weight loss & 49.8 & $1.06(0.48-2.36)$ & $1.26(0.32-4.88)$ \\
\hline BMI $\geq$ 85th percentile & 48.9 & $1.08(0.6-1.95)$ & $0.96(0.51-1.81)$ \\
\hline Constipation & 76.9 & $1.38(0.78-2.42)$ & $1.23(0.48-3.23)$ \\
\hline
\end{tabular}

$95 \% \mathrm{Cl}=95 \%$ confidence interval; $\mathrm{BMI}=$ body mass index; OR = odds ratio.

* Percentage of total dietary energy value. 
intestinal constipation. A study carried out at a functional intestinal constipation center of excellence in the South region of Brazil observed that this pathology predominated among female adolescents and also failed to detect an association between fiber intake and intestinal constipation. 28

With relation to the method used to evaluated whether fiber intake was adequate in line with recommendation, the formula of age +5 was used since the new recommendations (IOM, 2000/2005) deal with total fiber, which is the sum of dietary fiber + functional fiber. This new definition limits analysis because of the difficulty in identifying functional fiber, which is added to foods with a specific objective. For this reason, the criterion of dietary fiber was retained in this study.

The results indicate that excessive fat consumption and non-habitual consumption of beans are strongly associated with the risk of insufficient dietary fiber intake in both sexes. Furthermore, females suffer more risk factors for this outcome, such as overweight and dieting to lose weight. These data can be used as the basis for nutritional education programs for schools and health services, which should emphasize recovering Brazil's dietary habits from more than a decade ago, when cereals, pulses and vegetables predominated. ${ }^{5}$

\section{References}

1. Marlett JA, McBurney MI, Slavin JL; American Dietetic Association. Position of the American Dietetic Association: health implications of dietary fiber. J Am Diet Assoc. 2002; 102:993-1000.

2. Nicklas TA, Myers L, O'Neil C, Gustafson N. Impact of dietary fat and fiber intake on nutrient intake of adolescents. Pediatrics. 2000;105:E21.

3. Kant AK. Reported consumption of low-nutrient-density foods by American children and adolescents: nutritional and health correlates, NHANES III, 1988 to 1994. Arch Pediatr Adolesc Med. 2003; 157:789-96.

4. Harnack L, Stang J, Story M. Soft drink consumption among US children an adolescents: nutritional consequences. J Am Diet Assoc. 1999;99:436-41.

5. Monteiro CA, Mondini L, Costa RBL. Mudanças na composição e adequação nutricional da dieta familiar nas áreas metropolitanas do Brasil (1988-1996). Rev Saude Publica. 2000;34:251-8.

6. Matos LL, Martins IS. Consumo de fibras alimentares em população adulta. Rev Saude Publica. 2000;34:50-5.

7. Menezes EW, Giuntini EB, Lajolo FM. Perfil da ingestão de fibra alimentar e amido resistente pela população brasileira nas últimas três décadas. In: Lajolo FM, Saura-Calixto F, Witting de Penna E, Menezes EW, org. Fibra dietética en Iberoamérica: tecnología y salud: obtención, caracterización, efecto fisiológico y aplicación en alimentos. São Paulo: Varela; 2000. v. 1. p. 165-78.
8. Andersen LF, Nes M, Sandstad B, Bjorneboe GE, Drevon CA. Dietary intake among Norwegian adolescents. Eur J Clin Nutr. 1995;49:555-64.

9. Cavadini C, Siega-Riz AM, Popkin BM. US adolescent food intake trends from 1965 to 1996. Arch Dis Child. 2000;83:18-24.

10. Hurson M, Corish C. Evaluation of lifestyle, food consumption and nutrient intake patterns among Irish teenagers. Ir J Med Sci. 1997; 166:225-30.

11. Aguirre AN, Vitolo MR, Puccini RF, Morais MB. Constipação em lactentes: influência do tipo de aleitamento e da ingestão de fibra alimentar. J Pediatr (Rio J). 2002;78:202-8.

12. Araujo Sant'Anna AM, Calçado AC. Constipation in school-aged children at public schools in Rio de Janeiro, Brazil. J Pediatr Gastroenterol Nutr. 1999;29:190-3.

13. Morais MB, Vitolo MR, Aguirre AN, Fagundes-Neto U. Measurement of low dietary fiber intake as a risk factor for chronic constipation in children. J Pediatr Gastroenterol Nutr. 1999;29:132-5.

14. Zaslavsky C, De Barros SG, Gruber AC, Maciel AC, Da Silveira TR. Chronic functional constipation in adolescents: clinical findings and motility studies. J Adolesc Health. 2004;34:517-22.

15. Sotelo YO, Colugnati FA, Taddei JA. Prevalência de sobrepeso e obesidade entre escolares da rede pública segundo três critérios de diagnóstico antropométrico. Cad Saude Publica. 2004;20:233-40.

16. Anjos LA, Castro IR, Engstrom EM, Azevedo AM. Crescimento e estado nutricional em amostra probabilística de escolares no Município do Rio de Janeiro. Cad Saude Publica. 2003;19(Suppl 1):S171-9.

17. Organización Mundial de La Salud. Dieta, nutrición y prevención de enfermedades crónicas. Ginebra: OMS; 1990.

18. Williams $\mathrm{CL}$, Bollella $\mathrm{M}$, Wynder EL. A new recommendation for dietary fiber in childhood. Pediatrics. 1995;96:985-8.

19. World Health Organization. Physical status: the use and interpretation of anthropometry. Geneva: WHO; 1995.

20. Samuelson G. Dietary habits and nutritional status in adolescents over Europe. An overview of current studies in the Nordic countries. Eur J Clin Nutr. 2000;54 Suppl 1:S21-8.

21. Berenson GS. Childhood risk factors predict adult risk associated with subclinical cardiovascular disease. The Bogalusa Heart Study. Am J Cardiol. 2002;90:3L-7L.

22. Freedman DS, Khan LK, Serdula MK, Dietz WH, Srinivasan SR, Berenson GS. Inter-relationships among childhood BMI, childhood height, and adult obesity: the Bogalusa Heart Study. Int J Obes Relat Metab Disord. 2004;28:10-6.

23. Kimm SY. The role of dietary fiber in the development and treatment of childhood obesity. Pediatrics. 1995;96:1010-4.

24. Alfieri M, Pomerleau J, Grace DM, Anderson L. Fiber intake of normal weight, moderately obese and severely obese subjects. Obes Res. 1995; 3:541-7.

25. Ludwig DS, Pereira MA, Kroenke CH, Hilner JE, Van Horn L, Slattery ML, et al. Dietary fiber, weight gain, and cardiovascular risk factors in young adults. JAMA. 1999;282:1539-46.

26. Kromhout D, Bloemberg B, Seidell JC, Nissinen A, Menotti A. Physical activity and dietary fiber determine population body fat levels: the Seven Countries Study. Int J Obes Relat Metab Disord. 2001;25:301-6. 
52

Jornal de Pediatria - Vol. 83, No.1, 2007
Dietary fiber intake in adolescents - Vitolo MR et al.

27. Garaulet M, Martinez A, Victoria F, Pérez-Llamas F, Ortega RM, Zamora S. Difference in dietary intake and activity level between normal-weight and overweight or obese adolescents. J Pediatr Gastroenterol Nutr. 2000;30:253-8.

28. Garrigues V, Galvez C, Ortiz V, Ponce M, Nos P, Ponce J. Prevalence of constipation: agreement among several criteria and evaluation of the diagnostic accuracy of qualifying symptoms and self-reported definition in a population-based survey in Spain. Am J Epidemiol. 2004;159:520-6.
Correspondence:

Márcia Regina Vitolo

Rua Sarmento Leite, 245, Departamento de Saúde Coletiva, Sala 414

CEP 90050-170 - Porto Alegre, RS - Brazil

E-mail: marciavitolo@hotmail.com 